\title{
Closing the Sedentary Lifestyle Gaps: Investigating the Factors Influencing Exercise and Physical Activity Habits among Sandwich Students of University of Education, Winneba
}

\author{
Simon Kormla Donkor ${ }^{1, *}$, Munkaila Seibu ${ }^{2}$ \\ ${ }^{1}$ Department of Basic Education, University of Education, Winneba, Ghana \\ ${ }^{2}$ Department of Health, Physical Education, Recreation and Sports, University of Education, Winneba, Ghana \\ *Corresponding author: donkorsimon88@yahoo.com
}

Received January 19, 2019; Revised February 23, 2019; Accepted April 27, 2019

\begin{abstract}
In recent times, researchers have acknowledged the critical role of exercise and physical activity on the healthy wellbeing of an individual. Therefore, this study investigated the factors that influence exercise and physical activity habits of undergraduate sandwich students of the University of Education, Winneba (December-January, 2018/2019) session. A cross-sectional descriptive survey research design was employed to gather information on the respondents. The study sample was made up of one hundred and ninety-one (191) participants out of which 67 were males and 124 were females selected through census sampling. The findings of the study revealed that health and wellness factors predominantly influenced $(\mathrm{M}=3.60, \mathrm{SD}=0.75)$ sandwich students exercise habits followed by psycho-social factors $(\mathrm{M}=3.31, \mathrm{SD}=0.65)$, and other factors $(\mathrm{M}=3.13, \mathrm{SD}=0.86)$. Besides, the t-test results also showed no statistically significant differences between male and female sandwich students on their perception of health and wellness factors [t (189) $=0.702, \mathrm{p}=0.484$, 2-tailed], psycho-social [t (189) $=1.134, \mathrm{p}=0.258,2$-tailed], and other factors [ $\mathrm{t}(189)=0.885, \mathrm{p}=0.377,2$-tailed] at 0.05 alpha level. Furthermore, the ANOVA results disclosed that there were no statistically significant differences in their perception of health and wellness factors $[\mathrm{F}(2,188)=$ 1.049, $\mathrm{p}=0.352]$, psycho-social factors $[\mathrm{F}(2,188)=1.112, \mathrm{p}=0.331]$, and other factors $[\mathrm{F}(2,188)=0.697, \mathrm{p}=0.499$ ] at 0.05 based on age. Therefore, it was recommended the University through its health directorate should conscientize and reorient students on the benefits of engaging in regular physical activity.
\end{abstract}

Keywords: exercise habits, health and wellness, physical activity, psychosocial, sandwich students

Cite This Article: Simon Kormla Donkor, and Munkaila Seibu, "Closing the Sedentary Lifestyle Gaps: Investigating the Factors Influencing Exercise and Physical Activity Habits among Sandwich Students of University of Education, Winneba.” Journal of Physical Activity Research, vol. 4, no. 1 (2019): 73-79. doi: 10.12691/jpar-4-1-10.

\section{Introduction}

There is a general consensus that the quest to stay healthy should be seen as a pre-occupation of most individuals. Staying healthy should be seen and approached as an active lifestyle owing to the fact that the quality of life that someone enjoys is dependent on the proactive choices that are made. Therefore, exercise touted as a natural, inexpensive, reliable, most effective and efficient "miracle pill" the world has but now seems to have been thrown away [1]. Scholars in the field of physical education maintain that exercise is an antidepressant, a booster of the immune system and above all, a key that opens recreational, leisure and a competitive activities enjoyment. It is cheap, could be done by all persons, performed anywhere and not manufactured in any laboratory somewhere and packaged [2]. Accordingly, it could be said that exercise requires individual's commitment and involvement in other to reap its numerous health benefits since nobody can do it for the other. Appropriate physical activity is necessary at all ages for physiological fitness because it enhances individuals' capacity for everyday physical effort and movement without undue fatigue or discomfort. For instance, adults are advised to achieve a total of at least 30 minutes of leisure-time moderate physical activity, either in one session or in multiple sessions of at least 10 minutes duration, on five or more days of the week (150 mins per week). Moderate activity can be achieved through walking, cycling, gardening and housework, as well as various sports and exercises [3]. These expositions give credence to the importance of staying healthy through regular physical activity and exercise.

Despite the benefits that accrue to regular physical activity and exercise, reports across the world have continually revealed an upsurge of sedentary lifestyle 
which is proven to have dire consequences on an individual [4]. According to [5] unveils that physical inactivity increases the risk of developing heart diseases by 1.5 times partly because it raises the likelihood of developing significant risk factors for Non-Communicable Diseases such as hypertension, diabetes, and other cardiovascular diseases. The authors further submit that, nearly a quarter of all global ischemic heart disease is related to physical inactivity. On their part [6] also disclosed that physical inactivity is responsible for a large worldwide burden of the disease. In a similar reportage, [7] gave alarming health care costs emanating from lack of physical activity and exercise. In Ghana, scholars such as [8] have unveil that the decline in engaging in physical activity have led to the upsurge of overweight and obesity prevalence of between $7.8 \%$ and $25.9 \%$ from 2012 to 2018. In essence, to address the increasing trend of Non-Communicable Diseases, it is important to reduce the sedentary lifestyles.

[9] explicate that sedentary lifestyle is exhibited in excessive amount of daily sitting, be it to watch television, work behind the computer, or even reading. Its negative health influences include increased anxiety, cardiovascular disease, diabetes, depression and more. A sedentary activity level describes someone who gets little to no exercise. If you spend a lot of time sitting at a desk or watching television, without working out regularly, you are considered sedentary. Research suggests there is an increase in spinal load during sitting [10]. It is postulated that spinal loads are associated with rotation of the pelvis and spinal shrinkage and create a potential risk for the development of low back symptoms. However, a 2009 systematic review found no evidence for an association between leisure time sitting and low back pain [11]. Sedentary lifestyle therefore, relates to absence of physical activity and it reflected in long hours of sitting, watching television, reading, playing computer games etc. which potentially affect the general wellbeing of an individual and causes avoidable deaths.

Meanwhile, extant literature has documented several factors that influence the exercise and physical activity levels of any population. For instance [12] identified four main factors that act as barriers to attending exercise programmes: gender-specific, environmental, programme intervention, and person-based barriers. Adverse weather conditions such as cold, heat or rain deterred adults from participating in Physical Activity [13,14]; Being too busy or not having enough time [15,16]; Lack of interest, motivation, and discipline were cited as barriers [17]; [16] and Chronic pain in hands, feet, arms, legs, and back from arthritis and other degenerative diseases limited mobility or function and created barriers to Physical Activity [18].

As affirmed by [19] "the college years are a critical time for the development of positive and negative health behaviours that persist into later life” (p. 1134). Positive habits cultivated lives on till adult life as such it is imperative that college students develop exercise habit to reap the benefits of exercise in their college life. Informal observation showed that most people spend the majority of our time sitting - especially corporate working class and college students in Ghana. We sit in our cars, classrooms, offices, canteen, home, traffic, even in the toilet. This is what I called "sitting galore". The worst of all is that play time is now on screen of our televisions, computers and our mobile phones. The implication is less blood circulation and failing muscles. Several systematic reviews concluded that high levels of sitting time are associated with an increased risk of all-cause mortality $[20,21,22,23]$.

In the survey, there were a variety of quantitative questions which revealed that on average, college students did 3.42 days of moderate exercise, 2.66 days of vigorous exercise, and 2.18 days of strength-training over the past 7 days [24]. Moderate exercise was defined as a noticeable increase in heart rate such as a brisk walk; vigorous exercise was defined as exercise that causes large increases in breathing or heart rate such as jogging, and strength training was defined as using a resistance weight machine. The researchers concluded that exercise can potentially affect a person's body mass index. However, they also found that body mass index and the desire to lose weight could affect how much someone exercises. About gender differences, it was concluded that males are more likely to use exercise as a way to reduce weight, whereas females are more likely to use other means to lose weight [24].

In a study conducted by [4] on factors that affect exercise habits of college students revealed that, the top reasons college students exercised was to remain healthy $(\mathrm{M}=3.42$, SD $=0.64)$, to gain the positive feeling that comes from exercise $(\mathrm{M}=3.22$, $\mathrm{SD}=0.74)$; to join with friends who exercised $(\mathrm{M}=2.99$, $\mathrm{SD}=0.72)$; and when feeling overweight $(\mathrm{M}=2.96, \mathrm{SD}=0.88)$. Participants gave increased agreement to the item, "Having an increased homework load decreases the time I spend for exercise" ( $\mathrm{M}=3.10, \mathrm{SD}=0.86)$. Majority of the population cannot see the danger in all the sitting we do -especially when exercise is entirely ignored. Associations have also been found between sedentary behaviour and certain risk indicators for cardio-metabolic disease [25], suggesting possible mechanisms through which sedentary behaviour is contributing to poorer health. Higher levels of sedentary behaviour appear to be linked with higher waist circumference [26], body mass index (BMI) [27] and disease risk biomarkers such as glucose and triglycerides [28]. Prolonged sitting appears to be particularly detrimental for cardio-metabolic health.

Review of the empirical studies suggests that the factors that physical activity and exercise habits are many and diverse. However, these factors could be categorized as health and wellness factors (health reasons, loose/maintain body weight, trim stomach, etc), psychosocial factors (positive feeling, friend influence, enjoyment, appearance, building muscles etc), and other factors (bad weather, chronic pain, cold, heat, test/examination etc.). It is therefore expected that health and wellness reasons should dominate so as to curtail the occurrence of NonCommunicable Diseases (NCDs) in later life. However, scrutiny of the above factors indicates that the factors that influence physical activity and exercise habits are inconclusive. For instance, while [4] discovered that exercise habits was more related to health reasons, previous studies [12,29] revealed respectively in their separate studies that psychosocial and other factors dominants respondents exercise habits. By inference, it could be said that the factors that influence exercise habits is open to further scrutiny and research. 
Meanwhile, researchers have investigated the influence of demographic variables and exercise habits in different contexts. In their study, [6] discovered statistically significant differences between sex, age and students exercise motivation and physical activity. This result implied that the level of engagement of exercise and physical activity among students is contingent on whether they are male or female and their ages. Confirming this finding, [30] and [31] all observed that there is a significant difference between male and female students' motivation of exercise and physical activity. Departing from these findings, previous studies [32]; [33] have all revealed that even though male and female college students differ in their exercise habits, there was no statistically significant difference between male and female college students and their motivation for exercise and physical activity. Based on these conflicting, results, this study investigated the effect of sex and on the exercise and physical activity levels of the students.

A recent review has confirmed that the increased risk of cardio-metabolic outcomes such as cardiovascular disease and type 2-diabetes associated with excessive sedentary behaviour, remains even after controlling for leisure time participation in moderate/vigorous physical activity [20] Similarly, a systematic review has concluded that regardless of how the sedentary time was measured, those in the highest category of sedentary time had approximately twice the risk of developing diabetes or cardiovascular disease, or dying from cardiovascular disease, as those in the lowest sedentary time category [34]. Additionally, the trepidation emanating from [35] study that six out of every ten college students do not get the recommended amount of physical activity and exercises as enshrined by the [36] coupled with [37] caution that inadequate levels of physical activity and exercise leads to some health issues including obesity, cardiovascular disease, and increased risk for cancer gives credence to the need to explore the factors that influence the physical activity and exercise habits. The scary outlook of findings from the studies of recent past signals a call for action to increase exercise and physical activity bouts on University and College Campuses. Hence, the study investigated the factors that influence physical activity and exercise habits among sandwich students of University of Education, Winneba.

The following research questions were formulated and guided the study.

1. What factors influence exercise habits among Undergraduate Sandwich students of the Department of Basic Education, UEW?

The study also tested these hypotheses:

$\mathrm{H}_{01}$ : There is no statistically significant difference between male and female sandwich students on their perception of the factors influencing their physical activity and exercise habits.

$\mathrm{H}_{\mathrm{o} 2}$ : Age does not account for differences among sandwich students on their perception of the factors influencing their exercise habits.

\subsection{Theoretical Framework}

The theoretical model that underpinned this study was the Social Cognitive Theory [38] which is governed by perception and the desire to achieve positive outcomes and avoid negative ones. The theory takes into account a person's past experiences, which factor whether behavioral action will occur. These past experiences influence reinforcements, expectations, and expectancies, all of which shape whether a person will engage in a specific behaviour and the reasons why a person engages in that behaviour. The Theory of Reasoned Action, for example, proposes that an attitude towards performing behaviour is a function of the beliefs that one holds regarding the behaviour [39]. Thus, individuals are more likely to display behaviour if they hold favourable attitude or perception towards performing the behaviour [40]. This theory additionally emphasizes the relationship between the individual and the social world. Individual's conviction and behavioural intentions are fashioned by the communal context in which one finds himself or subjective norms related to the behavior. Clarification of health may make logic in relation to a specific social and ethnic context. For instance, People's perception about their body sizes may be affected by parental and peer group influences. Again, individuals' engagement in physical activity may also depend on the attitude of members of this social context especially the schools, religious bodies, parents, etc. toward participating in physical activity for health and wellbeing. This theory is in harmony with the study as one's quest to engage in physical activity or exercise could be predicted by the individuals around him/her or his/her own intuitive consciousness.

\section{Materials and Methods}

This study employed a cross-sectional survey design with the use of structured questionnaire which falls within the positivist/ deductive paradigm of developing quantitative data. This design provides a snapshot of how things are at a specific time, and entails the collection of data only once [41]. The rationale for the adoption of a survey design was that it relies on large-scale data from a representative sample of a population with the aim of describing the nature of existing conditions [42]. The choice of this design fits the study which sought to investigate the factors influencing sandwich students exercise habits. The population included all 2018/19 Post Diploma Sandwich students of the Department of Basic Education, University of Education, Winneba main campus, who reported for the December-January session.

Census sampling was used to select all the 252 sandwich students even though 191 (67 males \& 124 females) students were involved in the study. Census sampling involves collecting information from each and every person of interest [43]. The premise of this sampling strategy is that everybody's view is necessary to get a complete understanding of the issue. This sampling strategy was used to select all the sandwich students in the department. Factors Influencing Exercise Habits Questionnaire [4] was adopted for the study with modifications to categorize the factors into Health and Wellness, Psychosocial and Other Factors to suit the Ghanaian context. The structured questionnaire required participants to circle only one option to reflect their 
perception. Using questionnaire offers advantages in being able to obtain data more efficiently, economical in terms of time, energy and costs. Also, the use of the questionnaire provided an excellent means of measuring attitudes in a large population which can, therefore, be generalized to a larger population $[43,44]$. The exercise habits questionnaire consisted of 20 items categorized under Health and Wellness, Psychosocial and Other Factors. The questionnaire was made up of two sections. Section A focused on the background information of the students and Section B measured the variables measured on a 5-point Likert scale (1= Strongly Disagree; 2= Disagree; 3= Undecided; 4= Agree; and 5= Strongly Agree).

In this study, reliability was checked where the internal consistency of the instrument was measured using Cronbach's alpha where a coefficient of greater than 0.70 is deemed acceptable [45]. All the Cronbach alpha coefficients were above the 0.70 threshold for the three constructs (Health and Wellness, Psychosocial and Other Factors) which was indicative that the questionnaire was reliable. In checking for the face and content validity of the instrument, the instrument was given to some faculty members and a Professor in Physical Education. Recommendations relating to typographical mistakes, ambiguities, grammatical errors, and the expert advice were all incorporated in making the instrument very valid before its actual administration.

Before data analysis, the researcher read through the questionnaires, and removed those that were not answered or poorly answered. With the aid of the Version 22 Statistical Product for Service Solution (SPSS), the data were coded and analysed. Descriptive statistics such as frequencies, percentage, mean and stand deviation and inferential statistical tools such independent sample t-test, and one-way ANOVA were used to analyse the data. After satisfying the ethical conditions of anonymity, confidentiality, and informed consent the researchers selfadministered the instrument to the participants.

\section{Results/Discussion}

The demographic characteristics of the respondents are shown in Table 1. It could be seen from Table 1 more females $(n=124,64.9 \%)$ than males $(n=67,35.1 \%)$ participated in the study. The information also disclosed that majority of the respondents were $30-39$ years $(n=105$, $55.0 \%)$ than those $20-29(n=67,35.1 \%)$, and 40 and above $(n=19,9.9 \%)$ years whereas majority of the respondents were Post Diploma $1(n=130,68.1 \%)$ than Post Diploma 2 ( $n=61,31.9 \%$ ). The composition of the respondents based on the number of courses registered revealed that all the respondents $(n=191,100.0 \%)$ registered 6 courses. The proportion of respondents based on the number of hours of exercise per week disclosed that the proportion of those who exercised 1 hour per week $(n=102,53.4 \%)$ were more than 2 hours per week ( $n=59,30.9 \%)$, and 3 hours per week $(n=30,15.7 \%)$ respectively. The distribution of the respondents by whether they play for the university team revealed that majority indicated NO $(n=160,83.3 \%)$ whilst the rest $(n=31,16.2 \%)$ indicated YES. The demographic compositions of the respondents were vital to the study in two folds. Firstly, they confirmed that data were collected from a sample with varied backgrounds which suggested that the data were rich and representative of the population. Secondly, the demographic characteristics were used as the basis of comparison of the respondents on the study variables.

Research Question 1: What factors influence physical activity and exercise habits among Sandwich students of the Department of Basic Education, UEW?

This research question sought to explore the factors that influence undergraduate sandwich students exercise habits. The questionnaire was used to gather quantitative data to determine the nature and scope of exercise habits. Three kinds of exercise habits were identified in the study. These included health and wellness factors, psycho-social factors, and other factors. The results of the analysis were presented in Table 2.

The information in Table 2 revealed that respondents perceived all the factors outlined in the study to influence their exercise habits. However, using the sub scale mean, it could be observed that respondents rated highest on the health and wellness factors $(M=3.60, S D=0.75)$ followed by psycho-social factors $(\mathrm{M}=3.31, \mathrm{SD}=0.65)$, and other factors $(M=3.13, S D=0.86)$. However, based on the 5 -point Likert scale used in the questionnaire where the mean score is $3.0(1+2+3+4+5 / 5)$, it could be said that all the factors outlined in the study were rated above average. This implied that all the factors influencing exercise habits were common in the perception of the respondents.

Table 1. Demographic Characteristics of Respondents

\begin{tabular}{llll}
\hline Variables & & Frequency & Percentage \\
\hline \multirow{2}{*}{ Sex } & Male & 67 & 35.1 \\
& Female & 124 & 64.9 \\
Age & $20-29$ & 67 & 35.1 \\
& $30-39$ & 105 & 55.0 \\
Level & Above 40 & 19 & 9.9 \\
Courses Registered & Post-Dip 1 & 130 & 31.9 \\
\multirow{2}{*}{ Hours of Exercise Per Week } & Post-Dip 2 & 61 & 100.0 \\
& 1 & 191 & 53.4 \\
Do you Play for the University? & 2 & 102 & 30.9 \\
& 3 & 59 & 15.7 \\
\hline
\end{tabular}

Source: Field Data, 2019. 
Table 2. Descriptive Statistics on the Nature of Exercise Habits

\begin{tabular}{|c|c|c|c|c|c|}
\hline \multirow[t]{2}{*}{ Factors Influencing Exercise Habits } & \multirow[b]{2}{*}{ Item } & \multicolumn{4}{|c|}{ Response } \\
\hline & & A (\%) & U (\%) & D (\%) & M (SD) \\
\hline \multirow[t]{6}{*}{ Health and Wellness Factors } & 1 & $174(91.1)$ & $8(4.2)$ & $9(4.7)$ & $4.46(0.92)$ \\
\hline & 2 & $124(65.0)$ & 40 (20.9) & 27 (14.1) & 3.75 (1.13) \\
\hline & 3 & $102(53.4)$ & $36(18.8)$ & $53(27.8)$ & $3.37(1.30)$ \\
\hline & 4 & 69 (36.2) & $44(23.0)$ & 78 (40.8) & $2.91(1.29)$ \\
\hline & 5 & $113(59.2)$ & 27 (14.1) & 51 (26.7) & $3.54(1.34)$ \\
\hline & 6 & $110(57.6)$ & 30 (15.7) & $51(26.7)$ & $3.53(1.34)$ \\
\hline SSM (SSSD) & & & & & $3.60(0.75)$ \\
\hline \multirow[t]{10}{*}{ Psycho-Social Factors } & 7 & $159(83.3)$ & $20(10.5)$ & $12(6.2)$ & $4.07(0.92)$ \\
\hline & 8 & $104(54.4)$ & 39 (20.4) & $48(25.2)$ & 3.41 (1.16) \\
\hline & 9 & $129(67.5)$ & $28(14.7)$ & $34(17.8)$ & $3.77(1.27)$ \\
\hline & 10 & $86(45)$ & 47 (24.6) & $58(30.4)$ & $3.07(1.43)$ \\
\hline & 11 & $109(57.1)$ & 38 (19.9) & $44(23.0)$ & $3.16(1.25)$ \\
\hline & 12 & $103(53.9)$ & $42(22.0)$ & $46(24.1)$ & $3.39(1.11)$ \\
\hline & 13 & $80(41.9)$ & $31(16.2)$ & 80 (41.9) & $3.36(1.13)$ \\
\hline & 14 & 71 (37.1) & $42(22.0)$ & 78 (40.9) & $3.04(1.31)$ \\
\hline & 15 & $73(38.3)$ & $40(20.9)$ & $78(40.9)$ & $3.02(1.24)$ \\
\hline & 16 & 71 (37.1) & 30 (15.7) & 90 (47.1) & $2.90(1.38)$ \\
\hline SSM (SSSD) & & & & & $3.31(0.65)$ \\
\hline \multirow[t]{4}{*}{ Other Factors } & 17 & 99 (51.9) & $41(21.5)$ & $51(26.7)$ & $3.63(1.07)$ \\
\hline & 18 & $76(39.8)$ & $50(26.2)$ & 65 (34.1) & 3.09 (1.37) \\
\hline & 19 & 70 (36.6) & $53(27.7)$ & $68(35.6)$ & 3.05 (1.13) \\
\hline & 20 & 70 (36.6) & 36 (18.8) & 85 (44.5) & 3.01 (1.28) \\
\hline SSM (SSSD) & & & & & $3.13(0.86)$ \\
\hline
\end{tabular}

Source: Field Data, 2019.

Key: $\mathrm{D}=$ Disagree, $\mathrm{A}=$ Agree, $(\%)=$ Percentage, $M=$ Mean, $S D=$ Std. Deviation,

SSM $=$ Sub-scale Mean, SSSD = Sub-scale Std. Deviation.

Table 3. T-test Results for Male and Female Sandwich Students on Exercise Habits

\begin{tabular}{|c|c|c|c|c|c|c|}
\hline Factors Affecting Exercise Habits & Sex & Mean & Std. Dev. & $\mathbf{t}$ & df & P-Value \\
\hline \multirow{2}{*}{ Health and Wellness Factors } & Male & 3.58 & 0.67 & 0.702 & 189 & 0.484 \\
\hline & Female & 3.51 & 0.71 & & & \\
\hline \multirow{2}{*}{ Psycho-Social Factors } & Male & 3.38 & 0.68 & 1.134 & 189 & 0.258 \\
\hline & Female & 3.27 & 0.64 & & & \\
\hline \multirow{2}{*}{ Other Factors } & Male & 3.20 & 0.86 & 0.885 & 189 & 0.377 \\
\hline & Female & 3.09 & 0.85 & & & \\
\hline
\end{tabular}

Source: Field Data, 2019.

\subsection{Research Hypotheses}

$\mathrm{H}_{01}$ : There is no statistically significant difference between male and female sandwich students on their perception of the factors influencing their exercise habits.

$\mathrm{H}_{1}$ : There is a statistically significant difference between male and female sandwich students on their perception of the factors influencing their exercise habits.

This hypothesis sought to find out the perception of male and female sandwich students on their perception of the factors influencing their exercise habits. The independent samples t-test was used to analyze the results as shown in Table 3.

The t-test results in Table 3 showed that there were no statistically significant differences between male and female sandwich students on their perception of health and wellness factors [t (189) $=0.702, \mathrm{p}=0.484,2$-tailed], psycho-social [t $(189)=1.134, \mathrm{p}=0.258,2$-tailed], and other factors [t $(189)=0.885, \mathrm{p}=0.377,2$-tailed] at 0.05 alpha level. It could be inferred from the results that male and female sandwich students did not differ significantly on the factors influencing their exercise habits. Therefore, the null hypothesis that "there is no statistically significant difference between male and female sandwich students on their perception of the factors influencing their exercise habits" is accepted whilst the alternative hypothesis is rejected.

$\mathrm{H}_{\mathrm{o} 2}$ : Age does not account for differences among sandwich students on their perception of the factor influencing their exercise habits.

$\mathrm{H}_{2}$ : Age account for differences among sandwich students on their perception of the factors influencing their exercise habits.

A one-way between groups ANOVA test was employed to provide answers to this hypothesis, and the results are shown in Table 4.

The ANOVA results in Table 4 revealed that there were no statistically significant differences in their perception of health and wellness factors $[\mathrm{F}(2,188)=1.049$, $\mathrm{p}=0.352]$, psycho-social factors $[\mathrm{F}(2,188)=1.112, \mathrm{p}=0.331]$, and other factors $[\mathrm{F}(2,188)=0.697, \mathrm{p}=0.499]$ at 0.05 based on age. Therefore, this study concluded that the age of the sandwich students did not influence their perception of the factors influencing their exercise habits. Hence, the null hypothesis that "Age does not account for differences among sandwich students on their perception of the factors influencing their exercise habits" is accepted whilst the alternative hypothesis is rejected. 
Table 4. Mean, Standard Deviation and ANOVA Results for Age and Factors Influencing Exercise Habits

\begin{tabular}{|c|c|c|c|c|c|c|c|c|}
\hline Variables & Age & Mean & Std. Dev. & Sum of Squares & Df & Mean Square & $\mathbf{F}$ & Sig. \\
\hline \multirow{4}{*}{ Health and Wellness Factors } & $20-29$ & 3.47 & 0.67 & 1.012 & 2 & 0.506 & 1.049 & 0.352 \\
\hline & $30-39$ & 3.60 & 0.70 & 90.683 & 188 & 0.482 & & \\
\hline & Above 40 & 3.41 & 0.75 & 91.695 & 190 & & & \\
\hline & Total & 3.53 & 0.69 & & & & & \\
\hline \multirow{4}{*}{ Psycho-Social Factors } & $20-29$ & 3.23 & 0.63 & 0.946 & 2 & 0.473 & 1.112 & 0.331 \\
\hline & 30-39 & 3.37 & 0.67 & 79.932 & 188 & 0.425 & & \\
\hline & Above 40 & 3.24 & 0.61 & 80.878 & 190 & & & \\
\hline & Total & 3.31 & 0.65 & & & & & \\
\hline \multirow{4}{*}{ Other Factors } & $20-29$ & 3.08 & 0.85 & 1.024 & 2 & 0.512 & 0.697 & 0.499 \\
\hline & 30-39 & 3.19 & 0.88 & 137.960 & 188 & 0.734 & & \\
\hline & Above 40 & 2.96 & 0.76 & 138.984 & 190 & & & \\
\hline & Total & 3.13 & 0.86 & & & & & \\
\hline
\end{tabular}

Source: Field Data, 2019.

\subsection{Discussion of Results}

The purpose of this study was to measure the factors that influence exercise and physical activity habits of 2018/19 Post Diploma 1 and 2 sandwich students (December-January session) of the Department of Basic Education, University of Education, Winneba. The findings of the study showed that the sandwich students had a blend of factors influencing their exercise and physical activity habits. However, the results revealed that the sandwich students perceived health and wellness factors most to be influencing their exercise habits and physical activity, followed by the psycho-social factors while other factors was the least among the factors. This finding is congruent with [4] findings where health and wellness factors dominated college students exercise and physical activity levels than psycho-social and other factors. However, the finding of this study disagrees with previous studies by [12] and [29] where it was established that psychosocial and other factors dominants respondents exercise habits. It was also found that male and female sandwich students did not differ significantly in their perception of the factors that influence their exercise and physical activity which is consistent with previous studies [32,33] but departs from [30] and [31] findings where there was no statistically between sex and exercise and physical activity habits. Furthermore, it was found that sandwich students' age do not significantly affect their exercise and physical activity habits which is in agreement with [32] but is inconsistent with [31] where age significantly influenced college students exercise and physical activity habits.

\section{Conclusion and Recommendation}

The study was motivated by the fact that with the increasing level of Non-Communicable Diseases (NCDs) emanating from obesity and overweight tacit phenomena like the factors influencing exercise habits has come under scrutiny. Accordingly, this study has unveiled that health and wellness factors, psycho-social and other factors are the reasons expound by sandwich students for engaging in exercise and physical activities. With this exposé, it is essential that students are continually counselled on the benefit of regular exercise and physical activities so as to reduce the effects emanating from lack of regular exercises and physical inactivity such as diabetes, hypertension, and other cardiovascular diseases. The study disclosed that students' demographic factors (sex and age) do not significantly impact their perception of the factors influencing their exercise and physical activity habits. It is therefore recommended that these demographic variables (sex, and age) should not be considered in the execution of the plans such as seminars and symposiums on the need for regular exercise and physical activity habits.

\subsection{Suggestions for Further Studies}

It is proposed that apart from the study being carried out in other departments or the entire university to determine the factors that influence student exercise habits, it is also suggested that further studies should be carried out to explore the relationship between exercise habits, self-esteem and the quality of life so as to get a comprehensive picture of these variables.

\section{Acknowledgements}

We wish to acknowledge the 2018/2019 (December-January) sandwich students from the Department of Basic Education, University of Education, Winneba, who willingly and readily accepted to respond to the items in the questionnaire. I thank all those who in diverse ways shared their ideas to make this article a reality.

\section{References}

[1] Darlow, S. D. \& Xu, X. (2011). The influence of close others' exercise habits and perceived social support on exercise. Psychology of Sport and Exercise 12(1) 575-578.

[2] Haapala, E.A.; Lintu, N.; Eloranta, A.-M.; Venäläinen, T.; Poikkeus, A.-M.; Ahonen, T.; Lindi, V.; Lakka, T.A. (2018). Mediating effects of motor performance, cardiorespiratory fitness, physical activity, and sedentary behavior on the associations of adiposity and other cardiometabolic risk factors with academic achievement in children. Journal of Sports Science, 36(1), 2296-2303.

[3] Department of Health (2004). At Least Five a Week. Evidence on the Impact of Physical Activity and Its Relationship to Health. A report from the Chief Medical Officer. Department of Health, London.

[4] Eichorn, L.; Kayla, B., Taylor, S \& Samuel,P. A (2018). Factors That Affect Exercise Habits of College Students. Online Published: March 2, 2018. 
[5] Arsenault, B. J, Rana, J. S, Lemieux, I, Després, J.P, Kastelein, J. J. P, Boekholdt, S. M, Wareham, N. J, Khaw, K.T (2009). Physical inactivity, abdominal obesity and risk of coronary heart disease in apparently healthy men and women. International Journal of Obesity 34(2), 340-352

[6] Egli, M.S T, Bland, H.W., Melton, B. F., \& Czech, l R. PhD (2011). Influence of Age, Sex, and Race on College Students' Exercise Motivation of Physical Activity. Journal of American College Health, 59, 399-406.

[7] The International Congress on Physical Activity and Public Health (2006)

[8] Alangea, D. O., Aryeetey, R. N., Gray, H. L., Laar, A. K., \& Adanu, R. M. K. (2018). Dietary patterns and associated risk factors among school age children in urban Ghana. BMC Nutrition 4(22), 1-9.

[9] Butler, K. (2017). A Sedentary Lifestyle Can Harm You, Even If You Exercise. Retrieved on 9/7/2018 @ https://www.mnn.com/health/fitness-well-being/stories/asedentary-lifestyle-can-harm-you-even-if-you-exercise.

[10] Pope, M. H., Goh, K. L., \& Magnusson, M. L. (2002). Spine ergonomics. Annual Review of Biomedical Engineering, 4, 49-68.

[11] Chen, S. M., Liu, M. F., Cook, J., Bass, S., \& Lo, S. K. (2009). Sedentary lifestyle as a risk factor for low back pain: a systematic review. International Archives of Occupational and Environmental Health, 82(7), 797-806.

[12] Freene, N., Waddington, G., Chesworth, W., Davey, R., \& Cochrane, T. (2014). Community group exercise versus physiotherapist-led home-based physical activity program: Barriers, enablers and preferences in middle-aged adults. Physiotherapy Theory \& Practice, 30(2), 85-93.

[13] Newson, R. S., \& Kemps, E. B. (2007). Factors that promote and prevent exercise engagement in older adults. Journal ofAging and Health, 19, 470-481.

[14] Purath, J., Van Son, C., \& Corbett, C.F (2011). Physical activity: exploring views of older Russians- speaking Slavic immigrants. Nursing research and practice.

[15] Lim, K., \& Taylor, L. (2005). Factors associated with physical activity among older people-a population based study. Preventive Medicine, 40(1), 33-40.

[16] Whitehead, C., Wundke, R., \& Crotty, M. (2006). Attitudes to falls and injury prevention: what are the barriers to implementing falls and prevention strategies? Clinical Rehabilitation, 20, 536-542.

[17] DeForche, B., \& DeBourdeaudhuij, I. (2000). Differences in psychosocial determinants of physical activity in older adults participating in organized versus non-organized activities. The Journal of Sports Medicine and Physical Fitness, 40, 362-372.

[18] Cooper, K. M., Bilbrow, D., Dubbert, P. M., Kerr, K., \& Kirchner, K. (2001). Health barriers to walking for exercise in elderly primary care. Geriatric Nursing, 22(5), 258-262.

[19] Barnett, N., Clark, M., Linkletter, C., Loxley, M., Rogers, M., \& Ott, M. (2013). Peer associations for substances use and exercise in a college student social network. Health Psychology, 33(10), 1134-1142.

[20] Biswas, A., Oh, P. I., Faulkner, G. E., Bajaj, R. R., Silver, M. A., Mitchell, M. S., \& Alter, D. A. (2015). Sedentary time and its association with risk for disease incidence, mortality, and hospitalization in adults: a systematic review and meta-analysis. Annals of Internal Medicine 162(2), 123-132.

[21] Chau, J. Y., Grunseit, A., Midthjell, K., Holmen, J., Holmen, T. L., Bauman, A. E., \& Van der Ploeg, H. P. (2013). Sedentary behaviour and risk of mortality from all causes and cardio-metabolic diseases in adults: evidence from the HUNT 3 population cohort. British Journal of Sports Medicine, 49(11), 737-742.

[22] Stamatakis, E; Hamer, M; Dunstan, D (2011). Screen-Based Entertainment Time, All-Cause Mortality, and Cardiovascular Events: Population-Based Study with Ongoing Mortality and Hospital Events Follow-Up. Journal of the American College of Cardiology, 57(292-299).

[23] Thorp; A. A.; Owen, N, Neuhaus, M; and Dunstan, D. W. (2011). Sedentary Behaviors and Subsequent Health Outcomes in Adults: A Systematic Review of Longitudinal Studies, 1996-2011. American Journal of Preventive Medicine 41(2), 207-215.
[24] Barry, A. E., Whiteman, S., Piazza-Gardner, A. K., \& Jensen, A. C. (2013). Gender differences in the associations among body mass index, weight loss, exercise, and drinking among college students. Journal of American College Health, 61(7), 407-413.

[25] Chau J, Y, GrunseitAC, Chey T, Stamatakis E, Brown WJ, Matthews CE, et al. Daily sitting time and all-cause mortality: a meta-analysis. PLoS One. 2013; 8(11).

[26] Healy, G. N., Wijndaele, K., Dunstan, D. W., Shaw, J. E., Salmon, J., Zimmet, P. Z., \& Owen, N. (2008). Objectively measured sedentary time, physical activity, and metabolic risk: the Australian Diabetes, Obesity and Lifestyle Study (AusDiab). Diabetes Care, 31(2), 369-371.

[27] Mummery, W. K., Schofield, G. M., Steele, R., Eakin, E. G., \& Brown, W. J. (2005). Occupational sitting time and overweight and obesity in Australian workers. American Journal of Preventive Medicine, 29(2), 91-97.

[28] Brocklebank, L. A., Falconer, C. L., Page, A. S., Perry, R., \& Cooper, A. R. (2015). Accelerometer-measured sedentary time and cardiometabolic biomarkers: A systematic review. Preventive Medicive, 76, 92-102.

[29] Brevard, B. P and Ricketts, C.D (1996). Residence of College Students Affects Dietary Intake, Physical Activity, and Serum Lipid Levels. Journal of the American Dietetic Association 96(1):35-8.

[30] Lustyk, M. K. B., Widman, L. Paschane, A. E., \& Olson. K. C. (2004). Physical activity and quality of life: Assessing the influence of activity frequency, intensity, volume and motives. Behavioral Medicine. 30(1), 124-131.

[31] Tiggemann, M. \& Williamson, S. (2000). The effect of exercise on body satisfaction and self-esteem as a function of gender and age. Sex Roles 43(1), 119-127.

[32] Kilpatrick, M. Hebert, E. Bartholomew, J. (2005). College students' motivation for physical activity: differentiating men's and women's motives for sport participation and exercise. Journal of American College Health, 54(2), 87-94.

[33] Ingledew, D. K. \& Sullivan, G. (2002). Effects of body mass and body image on exercise motives in adolescence. Psychology of Sport and Exercise, 3(4), 323-338.

[34] Wilmot, E.G., Edwardson, C.L, Achana FA, Davies, M.J, Gorely, T, Gray, L.J, Khunti, K, Yates, .T, Biddle, S.J. (2012). Sedentary time in adults and the association with diabetes, cardiovascular disease and death: systematic review and meta-analysis. Diabetologia 55: 2895-2905.

[35] Sparling, P. (2007). Obesity of campus. Preventing Chronic Disease, 4(3). Retrieved from http:.//www.cdc.gov/ped/issues/2007/jul/06_0142.htm.

[36] The World Health Assembly (2004). Global Strategy on diet, physical activity and health. 57.17. p. 2.

[37] Barr-Anderson, D.J., laskea, M.N., Veblen-Mortenson and Farbakhsh, K (2012). A school-based, peer leadership physical activity intervention for $6^{\text {th }}$ graders: feasibility and results of a pilot study. Journal of Physical Activity and Health 9 (4) 492-499.

[38] Bandura, A, (1986). Social Foundations of Thought and Action: A Social Cognitive Theory. Englewood Cliffs, NJ: Prentice-Hall.

[39] Wang, Y., Liang, H. \& Chen, X. (2009). Measured body mass index, body weight perception, dissatisfaction and control practices in urban, low-income African American adolescents. BioMed Central Public Health 9,183.

[40] Conner, M., \& Sparks, P. (2005). The theory of planned behavior and health behaviors, in M. Conner and P. Norman (eds) Predicting health behavior $\left(2^{\text {nd }}\right.$ ed.). Buckingham: Open University Press.

[41] Bryman, A. (2008). Social Research Methods ( ${ }^{\text {rd }}$ Ed.). New York: Oxford University. California: Sage Publication.

[42] Cohen, L., Manion, L. \& Morrisson, K. (2011). Research methods in education $\left(7^{\text {th }}\right.$ ed.). London: Routledge

[43] Babbie, E., (2008). The Practice of Social Research (12 ${ }^{\text {th }}$ ed.). USA: Thomas Wadsworth.

[44] Sekaran, U. (2006). "Research methods for business: A skill building approach", ( $4^{\text {th }}$ ed.). New Jersey: John Wiley and Sons.

[45] Polit, D. F. \& Beck, C. T. (2010) Essentials of Nursing Research: Appraising Evidence for Nursing Practice. ( $7^{\text {th }}$ ed.), Wolters Kluwer Health/Lippincott Williams \& Wilkins, Philadelphia.). 